Background Disregulation of blood pressure (BP) and lipid metabolism is the basis of metabolic syndrome (MS), but interrelation of these MS components is not well studied today.

Aim To investigate influence of BP upon regulation of lipid metabolism in obese children.

Patients and Method 40 obese patients aged 10-16 years (13.9 \pm 0.27 y.o.) with high BP (HBP; $143.6 \pm 1.1 / 82.4 \pm 2.9 \mathrm{~mm})-1^{\text {st }}$ group. 40 obese patients with normal BP $(118.25 \pm 1.0 / 69 \pm 0.8 \mathrm{~mm}$, $\mathrm{p}<0.01)$ - comparison group ( $2^{\text {nd }}$ group). Examination included BP measurement and analysis of lipid profile.

Results Dyslipidemia in $1^{\text {st }}$ group was significantly more frequent than in $2^{\text {nd }}$ group: $85 \%$ versus $67.5 \%(p<0.05)$. Comparison of lipid spectrum showed that different disorders of lipid metabolism were more frequent and more significant in $1^{\text {st }}$ group in comparison with $2^{\text {nd }}$ : hypertriglyceridemia $-57.5 \%$ versus $22.5 \% \quad(p<0.01)$ and $2.36 \pm 0.15 \mathrm{mmol} / \mathrm{l}$ (mean value) versus $1.64 \pm 0.04 \mathrm{mmol} / \mathrm{l}(\mathrm{p}<0.01)$; decreased HDL-C $-37.5 \%$ versus $10 \%(p<0.01)$ and $0.91 \pm 0.01$ $\mathrm{mmol} / \mathrm{l}$ versus $1.03 \pm 0.02 \mathrm{mmol} / \mathrm{l}(\mathrm{p}<0.05)$; increased LDL-C $-45.0 \%$ versus $45.7 \%$ and $3.72 \pm 0.11 \mathrm{mmol} / 1$ versus $3.32 \pm 0.14 \mathrm{mmol} / \mathrm{l}$ $(p=0.06)$; increased index of atherogenicity $-75 \%$ versus $60 \%$ $(p<0.05)$ and $3.93 \pm 0.1$ versus $3.12 \pm 0.1(p<0.01)$.

Conclusion Arterial hypertension in obese children was associated with more frequent and significant disorders of lipid metabolism. So, arterial hypertension in obese children should be estimated as an additional risk factor of atherogenicity.

\section{THE ASSESSEMENT OF THE VITAMIN D SUPPLY IN POLISH CHILDREN AT THE AGE OF 9-12 YEARS - MULTICENTRE RESEARCH}

doi:10.1136/archdischild-2012-302724.1025

'D Chlebna-Sokol, ${ }^{2} \mathrm{~J}$ Golec, ${ }^{2} \mathrm{~J}$ Karalus, ${ }^{3} \mathrm{ZP}$ Halaba, ${ }^{4} \mathrm{E}$ Karczmarewicz, ${ }^{5} \mathrm{~J}$ Konstantynowicz, ${ }^{6} \mathrm{~B}$ Kulik-Rechberger, ${ }^{7} \mathrm{M}$ Niedziela, ${ }^{4} \mathrm{~A}$ Dobrzańska. ${ }^{1}$ Propedeutic Paediatrics and Bone Metabolic Diseases; ${ }^{2}$ Medical University of Lodz, Lodz; ${ }^{3}$ Medical University of Silesia, Katowice; 'The Children's Memorial Health Institute in Warsow, Warsow; ${ }^{5}$ University of Bialystok, Bialystok; ${ }^{6}$ University of Lublin, Lublin; 'University of Poznan, Poznan, Poland

Introduction It is universally known that the systemic deficiency of vitamin $\mathrm{D}$ may hamper the correct peak bone mass acquistion.

Aim The aim of the study was to determine the vitamin D supply in schoolchildren in Poland.

Patients and methods The study comprised 6 research centers from Poland. The healthy schoolchildren at the age of 9-11.99 were examined. In every child the liver metabolite of vitamin D was detected twice: after the winter and summer. The serum was analysed with the immunochemiluminescence method. The sufficient $25 \mathrm{OHD}$ serum concentration was recognized at range of 20-100 ng/ml

Results The 715 of children were examined. The greatest vitamin D shortages were observed in Szczecin and Białystok - in 95\% and in $90 \%$ children. In Katowice and Lublin the lower concentration was detected in 89\% and 88\% of children and in Łódź and Poznań in $77 \%$ and $74 \%$. The results of the $250 \mathrm{HD}$ improved considerably after the summer. The greatest shortages were obtained in Poznań and Szczecin - in 52.9\% and 42.1\%. In Łódź the decreased concentration was observed in $41.5 \%$ of children. The lowest shortages were revealed in Lublin, Białystok and Katowice- in 28\%, 26.3\% and $26.3 \%$.

\section{Conclusions}

1. The lower concentration of vitamin $\mathrm{D}$ in as many children indicates on adverse diet and climatic conditions.

2. The results of this study confirm the neccesity of the prophylaxis of vitamin D deficiency in schoolchildren in Poland

3. The considerable improvement of the $25 \mathrm{OHD}$ serum concentration after the summer may provide favourable influence of the sunlight.

\section{EXCESSIVE FLUORIDE INTAKE IS ASSOCIATED WITH HYPERPARATHYROIDISM AND HYPOTHYROIDISM IN CHILDREN AND ADOLESCENT, JEDDAH- SAUDI ARABIA}

doi:10.1136/archdischild-2012-302724.1026

${ }^{1} \mathrm{RM}$ Al-Raddadi, ${ }^{2} \mathrm{SM}$ Bahijri, ${ }^{2} \mathrm{~T}$ Al-Khateeb. ${ }^{1}$ Postgraduate Center for Family and Community Medicine; ${ }^{2}$ King Abdulaziz University, Jeddah, Saudi Arabia

Background Exposure to Fluoride $(F)$ has increased significantly, so that individuals may be consuming more than recommended. Reported effects of excessive intake include reduced serum free thryroxine (FT4), triiodothyronine (FT3), calcium and increased parathyroid hormone (PTH) concentration.

Objective To investigate the prevalence of excessive Fluoride intake in apparently healthy children and adolescents, and explore its association changes in thyroid and parathyroid function in Jeddah-Saudi Arabia.

Methods 145 apparently healthy children and adolescents were recruited. 60 individuals satisfied selection criteria, and agreed to be enrolled. Subjects were examined dentally and clinically. Weights and heights were measured to calculate body mass index. Dental hygiene practices and fluoride intakes were recorded using recall method and food frequency questionnaires. Blood samples were obtained for the estimation of free thyroxine, triiodothyronine, thyroid stimulating hormone, Parathyroid hormone, calcium and phosphate. Fluoride was estimated in a samples of drinking water, beverages, and fasting urine of subjects. Total Fluoride intakes were calculated and used to subdivide groups into high and low or optimal intake subgroups.

Results Excessive Fluoride intake was identified among $36.7 \%$ of the individuals.

Calculated intake correlated with urinary excretion $(\mathrm{r}=0.54$, $\mathrm{p}=0.0003$ ).

Significantly higher mean thyroid stimulating hormone and Parathyroid hormone and lower mean of free thyroxine, triiodothyronine, calcium and phosphate were found in various high intake subgroups, with some subjects having abnormal values.

Conclusion Excessive F intake is common, and is associated with hyperparathyroidism and hypothyroidism in studied population.

\section{MINERAL PROFILE OF PNEUMOCOCCAL DISEASES IN THE CHILDREN}

doi:10.1136/archdischild-2012-302724.1027

${ }^{1} \mathrm{OM}$ Horlenko, ${ }^{2} \mathrm{VI}$ Rusyn, ${ }^{2} \mathrm{OO}$ Boldizhar, ${ }^{2} \mathrm{FV}$ Horlenko, ${ }^{2} \mathrm{NY}$ Kishko, ${ }^{1} \mathrm{AO}$ Yankovska, ${ }^{3} \mathrm{OM}$ Moskal, 'OA Pushkarenko, 'Al Tomey, 'GB Kosssey. 'Pediatrics and Infectious Diseases; ${ }^{2}$ Surgical Diseases; ${ }^{3}$ Internal Medicine, Uzhgorod National University, Medical Faculty, Uzhgorod, Ukraine

Background and Aims A mineral homeostases is assotiation of processes of sorbtion, distributing, and elimination of mineral composition. Mineral matters play an important role in maintenance of acid-basic balance, osmolality, participate in the function of many enzymic systems, assists development of inflammatory process.

Methods Focus group included 21 children, aged $11.1 \pm 0.95$ with community-acquired pneumonia, Pneumonia lower lobes acuta (PLA) in which was identificate S.Pneumonia.

Result In the majority of cases the results of physical examination were satisfactory. The level of zinc in blood plasma of PA patients were $0.68 \pm 0.17 \mathrm{mkg} / 1,0,670.03 \mathrm{mkg} / \mathrm{l}$ in urine, copper $-0.42 \pm 0.03$ $\mathrm{mkg} / \mathrm{l}$ in blood plasma, $0.36 \pm 0.02 \mathrm{mkg} / \mathrm{l}$ in urine, iron- $0.75 \pm 4.2$ $\mathrm{mkg} / \mathrm{l}$ in blood plasma, $23.48 \pm 1.75 \mathrm{mkg} / \mathrm{l}$ in urine, phosphorus $473.10+11.25 \mathrm{mkg} / \mathrm{l}$ in blood plasma, $312.50+11.84 \mathrm{mkg} / \mathrm{l}$ in urine, iodine $-70.23 \pm 5.81 \mathrm{mkg} / \mathrm{l}$ in blood plasma, $60.19 \pm 1.21 \mathrm{mkg} / \mathrm{l}$ in urine. There were a positive correlation with the levels of $\mathrm{Fe} / \mathrm{Cu}$ of blood serum $(r=0.64)$. With the level of calcium ratio of $\mathrm{Fe} / \mathrm{Cu}$ had a 
significant negative correlation $(\mathrm{r}=-0.87)$. Increase of $\mathrm{Cu}$, Fe levels in the patients with PA were identificate in the prevalence cases.

Conclusions Microelement status of patients with pneumonia is characterized by synergistic correlation between Fe and $\mathrm{Cu}(\mathrm{r}=0.64)$, and reverse dependence between $\mathrm{Ca}$ and $\mathrm{Fe} / \mathrm{Cu}(\mathrm{r}=-0.87)$.), increase of $\mathrm{Cu}, \mathrm{Fe}$ levels. Our dates show the dynamics of development of inflammatory process in Lung and possible role of violations of microelement status of child in pathogeny of diseases of breathing organs.

\section{8 \\ RESPIRATORY CHAIN DISORDERS: REVIEW OF 16 CASES}

doi:10.1136/archdischild-2012-302724.1028

J Sales Marques, Al Pinto Pais, D Rocha, A Vieira, H Santos. Centro Hospitalar Vila Nova de Gaia/Espinho EPE, Vila Nova de Gaia, Portugal

Introduction Respiratory chain disorders (RCD) are a heterogeneous group of diseases associated with multisystemic disorders. The diagnosis should be considered if there are 2 major criteria or 1 major and 2 minor criteria (Modified Walker Criteria).

Purpose Medical records of 16 cases of RCD diagnosed in Metabolic Unit of our hospital, between 2005 and 2010 were analyzed.

Results The results showed that all the patients have psychomotor delay and more than half cases hypotonia, strabism and adquired microcephaly at presentation. Other symptoms were multisystem such as: neurossensorial deafness (1/16), mioclonic epilepsy (3/16), intestinal duplication (1/16), ductus arterious persistent (1/16), renal hypopasia (2/16). We found important association with endocrinological changes (9/16), hypothyroidism in most situations, but also hypoparathyroidism, insipidus diabetes, growth hormone defect and hyperinsulinemia. Complex 2 deficiency was the most common cause of RCD (8/16). In one case we found depletion in mitochondrial DNA. No histopathology abnormalities were found in the muscle biopsy. Only (8/16) exhibited elevated plasma lactate. The treatment with Coenzyme Q10, carnitine and ketogenic diet seemed to improve their clinical course (less epileptic crisis after ketogenic diet $-6 / 6$, better concentration after coenzyme Q10 - 6/16, less hypotonia after carnitine -5/11).

Discussion and Conclusion Mitochondrial cytopathies should be considered in patients with an unexplained combination of neuromuscular and/or nonneuromuscular symptoms, with a progressive course, even if oxphos studies are normal.

Endocrinological changes are an important association of respiratory chain disorder and hormone screening must be included in all the patients with this metabolic disease.

\section{GLYCINE SUPPLEMENTATION IMPROVES THE CONCENTRATION, SOCIALIZATION, PERCEPTION AND AUTONOMY OF PATIENT WITH CREATINE TRANSPORT DEFECT}

doi:10.1136/archdischild-2012-302724.1029

J Sales Marques, D Rocha, Al Pinto Pais. Centro Hospitalar Vila Nova de Gaia/Espinho EPE, Vila Nova de Gaia, Portugal

Introduction Creatine transport defect (CTD) is a x-linked disorder with neurological symptoms. Glycine can help inhibit the neurotransmitters and supply the body with glucose needed for energy. Also act as a creatine precursor.

Purpose Treat with oral glycine in the period of 12 months, a patient with CTD and compare the clinical, analytic and brain magnetic resonance spectroscopy results, before and after therapy.

Material A fourteen year-old boy with CTD diagnosed at the age of five years, treated unsuccessfully with daily $20 \mathrm{mg}$ of oral methylphenidate for is behaviors disturbances.

Method Oral glycine in a dose of $250 \mathrm{mg} / \mathrm{kg} /$ day, divided in two doses.
Results After 12 months, we found some improvement in concentration, socialization, perception and autonomy. No evolution of speech. The creatine peak was slightly better than before (5 to $8 \mathrm{~mm}$ ). Urine creatine level reduces from 24427 to $10994 \mu \mathrm{mol} /$ mmol creatinine.

Discussion We believe that the clinical and analytic evolutions are associated with increase creatine peak level secondary to oral glycine. Glycine, because of is inhibitory action over the neurotransmitters, in research studies has shown that helps improve memory retrieval loss in those patients that suffer from a wide variety of sleep-depriving conditions, including schizophrenia, Parkinson and Huntington diseases. He also has a sedative effect and is used in attention-deficit, by reducing the excitability of nerves cells. Glycine is useful in patients with CTD and should be encouraged to use because has no side effect and can improve some behaviours disturbances that is common in this disease.

\section{A CASE OF RHIZOMELIC CHONDRODYSPLASIA PUNCTATA IN NEWBORN}

doi:10.1136/archdischild-2012-302724.1030

N Karabayir, G Keskindemieci, E Adal, 0 Korkmaz. Kanuni Sultan Suleyman Training and Research Hospital, Istanbul, Turkey

Rhizomelic chondrodysplasia punctata is an rare autosomal recessive peroxisomal disease. The main features of the disease are shortening of the proximal long bones, punctate calcifications in the metaphysis and epiphysis of long bones and the thoracic and lumbar vertebrae, dysmorphic face, and severe growth retardation, whereas cervical spinal stenosis may also rarely be present. Imaging of the brain and spinal cord in patients with this disorder may aid prognosis and guide management decisions. We report the newborn diagnosed as rhizomelic chondroplasia punctata with cervical stenosis. As far as we know, our case is the first case of autosomal recessive form with a cervical spinal stenosis detected in the neonatal period.

\section{AMINOACIDOPATHIES: REVIEW AND DATA OF 12 YEARS EXPERIENCE FROM A SPANISH TERTIARY CARE CENTER}

doi:10.1136/archdischild-2012-302724.1031

L Ferreras Antolín, E Moreno Medinilla, J Blasco Alonso, V Navas López, J Serrano Nieto, A Urda Cardona, A Jurado Ortiz, C Sierra Salinas. Hospital Marterno Infantil Carlos Haya, Málaga, Spain

Background/Aims Range and severity of symptoms hugely variable in aminoacidopathies, mainly diagnosed during acute episodes. Tandem Mass spectrometry (Ms/Ms) used in our unit since 2010 for diagnosing asymptomatic infants (very important for prognosis).

Methods Retrospective, descriptive study in which field data were collected from clinical histories of patients diagnosed of aminoacidopathies (excluding phenylcetonuria) since 2000 till 2012.

Results 30 children detected. 22/30 male; 24/30 caucasians.

$10 / 30$ diagnosed by newborn screening, all of them asymptomatic: 1 methylmalonic acidemia (MMA), 3 glutaric aciduria type 1, 2 homocystinuria, 2 methylcrotonylglycinuria, 1 hipermetioninemia and 1 maple syrup urine disease.

20/30 diagnosed because of clinical symptoms, 2/20 since MS/ MS newborn screening was performed. Mean age of clinical debut in intoxication type aminoacidopathies was 64.5 days (median 8 days). Most frequent symptoms were clouding of consciousness $(9 / 20)$, convulsions $(2 / 20)$ and apnoea $(2 / 20)$. Laboratory results showed metabolic acidosis (6/20), hyperammonemia (8/20), coagulation defects (4/20) and hipoglycemia. Main complications were: shock $(9 / 20)$, multiple organ failure $(5 / 20)$, coagulopathy $(4 / 20)$, brain injury $(1 / 20)$, liver failure $(1 / 20)$ and seizures $(2 / 20)$. The final diagnosis was: 5 OTC-defficiency, 2 citrullinemia, 3 methylmalonic 